\title{
Patient Reported Outcome
}

National Cancer Institute

\section{Source}

National Cancer Institute. Patient Reported Outcome. NCI Thesaurus. Code C95401.

Information collected directly from a patient that typically includes subjective feelings regarding symptoms, functions in daily life, physical, mental, emotional, spiritual, and social well being, and satisfaction with his/her health care. 